\title{
Cultural dimensions of teacher job satisfaction in a collectivist context
}

\author{
Bahadır Özcan \\ Adiyaman University, Turkey
}

\begin{abstract}
Culture is a broad context that has the potential to affect teachers' job satisfaction. The present study investigated the relationships between self-construal and teacher job satisfaction in a collectivist culture. Participants of the study were 426 individuals from primary, secondary, and high schools (1st-12th grades) in a mid-sized city. Stepwise multiple regression analyses were used in the data analysis. The findings suggested that relational vertical, humanistic, and personal self-construal significantly predicted intrinsic satisfaction. Furthermore, collective horizontal and humanistic self-construal significantly predicted extrinsic satisfaction. Finally, collective horizontal, humanistic, and personal self-construal significantly predicted job satisfaction (total). These findings provide strong evidence of the explanatory power of selfconstrual in intrinsic satisfaction, extrinsic satisfaction, and job satisfaction (total).
\end{abstract}

Keywords: Intrinsic satisfaction; Extrinsic satisfaction; Culture; Self-construal; Teacher

Article History: Submitted 22 February 2020; Revised 23 June 2021; Published online 30 June 2021

\section{Introduction}

The teaching profession is being practiced in a socio-cultural context. Therefore, understanding the relationship between culture and job satisfaction makes an extensive contribution to understanding job satisfaction. Teachers' job satisfaction is considered a master key to the quality of teaching and higher academic performance (Alderman, 2004). It simply refers to teachers' overall attitude and views toward their working conditions and profession (Hongying, 2007). Pepe et al. (2017) distinguish two main perspectives in the literature regarding job satisfaction: One perspective stresses the importance of personal factors for job satisfaction (e.g., cultural background, motivation for the profession, perception of student-teacher relations). Another perspective considers work and societal conditions (e.g., leadership style, salary, organizational equity). Teachers' job satisfaction is important so that it contributes to the effectiveness of administration (Hongying, 2007), work enthusiasm (Hongying, 2007; Li \& Wang, 2016), psychological health (Shoshani \& Eldor, 2016; Skaalvik \& Skaalvik, 2011), the effectiveness of teaching (Skaalvik \& Skaalvik, 2014; Kunter et al., 2013), the effectiveness of school functioning

Address of Corresponding Author

Bahadır Özcan, PhD, Deparmant of Special Education, Education of Gifted and Talented, Faculty of Education, Adiyaman University, 02040, Adiyaman, Turkey.

$\triangle$ baozcan@adiyaman.edu.tr

0000-0003-4278-8417

How to cite: Özcan, B. (2021). Cultural dimensions of teacher job satisfaction in a collectivist context. Journal of Pedagogical Research, 5(2), 222-236. http:// dx.doi.org/10.33902/JPR.2021270445 
(Shoshani \& Eldor, 2016), motivation and commitment (Li \& Wang, 2016; Shoshani \& Eldor, 2016). A teacher has an important position in the education system, so that teachers' job satisfaction affects the other school-based outcomes.

Individual-level culture (self-construal) is one of the variables contributing to explaining teachers' job satisfaction. Kwantes (2010) showed that national context differences are related to job satisfaction. The goal of the current study was to examine the effects of individual-level culture (self-construal) on teachers' job satisfaction. Understanding relationships between individual-level culture and job satisfaction might direct the researcher and the school community to explore culturally sensitive school environments for each culture.

\subsection{Job Satisfaction}

Job satisfaction is vital for an institution's success and is a crucial source of employee motivation (Elizabeth \& Zakkariya, 2018). Researchers have not agreed upon a standard definition. They have put forward different definitions according to their perspectives on job satisfaction. Job satisfaction is a pleasurable emotional mood that follows from evaluating someone's work experiences (Locke, 1976). Job satisfaction or dissatisfaction is considered a function of the perceived relationship between what a person demands, what he/she gets from work, and how much value he/she attributes to it (Kemelgor, 1982). Job satisfaction expresses people's feelings toward the awards they receive at work (Lawler, 1990). Moreover, job satisfaction is an attitude toward work resulting from job perception and harmony between the individual and the organization. It includes how individuals feel about their work and the various features of that work (Spector, 1997). Job satisfaction is "likely to be in part socially determined, being embedded in the network of meanings and values of a particular cultural tradition" (Warr, 2007, p. 283).

Job satisfaction can be affected by a variety of situational job characteristics. Intrinsic and extrinsic satisfaction are two fundamental determinants of job satisfaction (Buitendach \& De Witte, 2005). One of the well-known situational approaches to job satisfaction is Herzberg (1987) and Herzberg et al.'s (2010) two-factor theory, which clearly explains the two-dimensional proposals that affect work attitudes. They highlight the factors that characterize the events at work that lead to extreme job satisfaction (intrinsic factors) and extreme dissatisfaction (extrinsic factors). Intrinsic factors refer to determinants that arise from doing the job and experiencing a sense of accomplishment, such as success, recognition, responsibility, and progress. Sources of intrinsic satisfaction are within the employee and last longer than extrinsic sources (Atchison, 1999; Herzberg, 1987; Herzberg et al., 2010). Extrinsic factors are received from the reward given to an employee, such as supervision, interpersonal relationships, working conditions, and salary. They are referred to as dissatisfaction factors, as they are necessary to prevent dissatisfaction. Extrinsic factors are also beyond the control of the employee (Herzberg et al., 2010).

Similarly, Hackman and Oldham's (1976) job characteristics theory implies five job characteristics: autonomy, job identity, task significance, skill diversity, and job feedback, which influence personal and organizational outcomes. Based on a comprehensive review of approaches (Warr, 2007), it provides the most extensive compilation of job characteristics that are significantly and positively linked to job satisfaction: (1) opportunity for personal control (employee appreciation, autonomy, self-determination), (2) communication with others (quantity and quality of interactions), and (3) supportive supervision (leader evaluation, supportive management). All features of the work and organization may affect employees' job satisfaction.

Determinants of job satisfaction vary according to the approaches. Vroom (1982) identified the factors that contribute to job satisfaction: work pace, ability to interact with colleagues, and acceptance from colleagues. According to Robbins (1996), fundamental elements lead to enhanced job satisfaction, supportive working conditions, and supportive and friendly colleagues. Job satisfaction depends primarily on employees' relationships with their colleagues. Employees with supportive and friendly colleagues are more satisfied with their jobs (Mottaz, 1985; Robbins, 1996). Job satisfaction consists of employees' attitudes toward their jobs, and employees' attitudes and 
feelings toward their work experiences significantly influence their performance (Elizabeth \& Zakkariya, 2018). An increase in job satisfaction is related to some positive outcomes: creativity (Dickson \& Lorenz, 2009), job performance (Dickson \& Lorenz, 2009; Elizabeth \& Zakkariya, 2018; Judge \& Bono, 2001; Riketta, 2008), and absenteeism (Dickson \& Lorenz, 2009). In short, job satisfaction is crucial due to many positive outcomes.

\subsection{Teacher Job Satisfaction}

Caprara et al. (2003) regarded job satisfaction as a "determinant factor" affecting teachers' attitudes and performance in educational contexts. A teacher's job satisfaction refers to a teacher's affective relations with the teaching role and is the result of the perceived relationship between what one wants from the teaching profession and what the teaching profession offers to him/her (Zembylas \& Papanastasiou, 2004). Teaching is often a stressful job, with demands from students, colleagues, administrators, and parents combined with excessive workload, changing policies, and lack of recognition of success (Greenglass \& Burke, 2003). However, teachers' job satisfaction stems from everyday school activities such as working with supportive colleagues, working with children, seeing students' progress, and the general school atmosphere (Cockburn \& Haydn, 2004).

There are three categories of sources of teachers' job satisfaction: (a) determinants that are internally linked to the teaching profession, (b) school-based determinants, and (c) determinants outside of school (Dinham \& Scott, 1998). Determinants that are intrinsically connected to teaching relate to actual teaching, working with students, and seeing what students learn and develop; these internal factors are often the primary motives for becoming a teacher and staying with the teaching profession (Moses et al., 2017). Contextual factors at school include relationships with students, colleagues, parents, school leadership, and school values (Dinham \& Scott, 1998).

Recent research has indicated that teacher job satisfaction is related to personality characteristics (Ayan \& Kocac1k, 2010), teacher-student relationships (Admiraal et al., 2019; Veldman et al., 2016), administrators' leadership style (Bogler, 2001), teacher burnout (Brouwers \& Tomic, 2000; Caprara et al., 2006; Greenglass \& Burke, 2003; Skaalvik \& Skaalvik, 2010), leaving the teaching profession (Ingersoll, 2001; Skaalvik \& Skaalvik, 2011; Chen, 2010), teacher autonomy and self-efficacy (Skaalvik \& Skaalvik, 2014), attrition (Perrachione et al., 2008), job performance (Caprara et al., 2003; Caprara et al., 2006; Greenglass \& Burke, 2003; Judge et al., 2001), teacher retention (Schaufeli \& Salanova, 2007), and teacher commitment (Ingersoll, 2001; Reyes \& Shin,1995). Job satisfaction has been associated with many variables, revealing that the relationship between job satisfaction and cultural context may contribute to a better understanding of job satisfaction.

Teachers can experience job satisfaction individually, but the teaching profession is performed in a sociocultural context. Teachers' interactions with colleagues and students affect their job satisfaction and motivation, but the cultural context and cultural values can also affect them (Huang \& Van de Vliert, 2004; Yetim \& Yetim, 2006). Increasing research highlights the relationship between teachers' job satisfaction and job-related factors. However, the cultural context influencing teachers' job satisfaction must be further explored.

\subsection{Self-Construal}

Culture is one of the contexts that contributes to understanding and explaining human behavior. Hofstede (1980) and Hofstede et al. (2010) defined national culture as "the programming of the mind" that has a widespread influence on values and behaviors. Triandis (1989) and Marcus and Kitiyama (1991) rejected a national cultural view of the determinants of cognition, emotion, behavior, and motives in favor of an approach that takes into account the construction of human behavior at the individual level, self-construal, within a particular national cultural environment. Self-construal is related to a person's knowledge and perceptions about his/her personality traits, social roles, experience, and future goals (Fiske \& Taylor, 1991; Gelfand et al., 2006). It has a multidimensional structure that reflects "the set of thoughts, feelings, and actions related to one's relationship with others and the self unlike others" (Singelis, 1994, p. 581). Kağıtçıbaş1 (2017) and 
Markus and Kitayama (1991) conceptualized self-construal as a personality trait that forms individuals' cognition, emotion, motivation, and behavior.

The present study's starting point proposed that self-construal can play a role in teachers' job satisfaction. This hypothesis is derived from culture, psychological, and cognitive processes at the individual level-aspects of the individual self in relation to others, different situations, and cultural settings (Haberstroh et al., 2002). In other words, self-construal is formed by a series of factors that present a set of "possible selves" under different conditions (Oyserman et al., 2004). Markus and Kitayama (1991) categorized self-construal as independent and interdependent. People with strong independent self-construal see themselves as autonomous entities and value individual uniqueness and self-expression (Christopher et al., 2010). In contrast, individuals with a strongly interconnected sense of self have a self-perception defined primarily by relationships with social environments (Christopher et al., 2010). Indeed, models containing different dimensions of self-construal have been proposed to explain self-construal.

Recently to describe self-construal more comprehensively Harb and Smith (2008) proposed and confirmed a self-construal model with six dimensions; vertical-relational self-construal, horizontalrelational self-construal, vertical-collective self-construal, horizontal-collective self-construal, personal self-construal, and humanity-bound self-construal. The personal self-construal dimension of Harb and Smith (2008) is alike to Markus and Kitayama's (1991) independent self-construal. It refers to the personal or individualized dimension of the self that tries to differentiate from the others; it does so with its own and independent self-presentations. Relational and collective selfconstruals are related to Markus and Kitayama's interdependent self-construal. However, relational self-construal refers to a view of the self that is associated with one's dyadic or small group relationships (e.g., friends, family) and collective self-construal refers to a view of the self as represented by one's membership in a larger, more distal group unified by shared norms and values (e.g., cultural group) (Harb \& Smith, 2008). They also extended the conceptualization of relational and collective self-construal by differentiating between vertical relationships (i.e., hierarchical, unequal) and horizontal relationships (i.e., equal). The relational and collective selfconstruals focus on the adoption and acceptance of the roles and norms associated with the group to which it belongs. The sixth dimension of self-construal is humanistic, which reflects the extent to which individuals' thoughts, feelings, and behaviors are formed by their views of themselves as part of a universal human culture (Harb \& Smith, 2008). We used Harb and Smith's Sixfold SelfConstrual Scale (SSCS), which has adequate reliability and validity estimations (Harb \& Smith, 2008).

Self-construal provides a more direct link between values and a range of work orientations and behaviors (Triandis, 2004). Recent research indicated that self-construal is associated with life satisfaction (Moza et al., 2021; Suh et al., 2008; Wei et al., 2020), subjective well being (Cheng et al., 2016; Cheng et al., 2011; Novin, et al. 2014; Özcan, 2017; Yamaguchi \& Kim, 2015; Yu et al., 2016), happiness (Wei et al., 2020), well-being (Maulana et al., 2021; Park et al., 2017), psychological wellbeing (Duncan et al., 2013), and academic satisfaction (Sheu et al., 2014). Specifically, Kirkman and Shapiro (2001) revealed that job satisfaction and work commitment are higher for collectivists due to low resistance to teamwork and increased willingness to delay management decisions. Yetim and Yetim (2006) indicated that collectivism is positively associated with job satisfaction. Hui and Yee (1999) emphasized a strong association between collectivism and job satisfaction. In Brazil, where people tend to accept others, such expatriates are also likely to have more satisfying communication in the workplace, which is an essential aspect of job satisfaction (Spector, 1997). Although these explanations have been increasingly influential in the field, little research has sought to integrate these insights into culturalist explanations of job satisfaction. We proposed relationships between different dimensions of self-construal and job satisfaction in a collective cultural context. 


\subsection{Present Study}

There is little research investigating job satisfaction and its cultural determinants in a collectivist culture context. Determining factors of job satisfaction may not be universal across cultures; it may vary in levels of significance based on differences in self-construal. Harb and Smith's (2008) six dimensions individual level self-construal model can be used to show how dimensions of selfconstrual would influence job satisfaction. Turkey is considered to be primarily collectivist (Hofstede et al., 2010). Furthermore, Turkish culture assigns importance to close interpersonal relationships, including those with family members, relatives, and close neighbors (Kağıtçıaşı, 2017; Uskul et al., 2004). More specifically, the study examined how teachers' self-construalrelational vertical self-construal, relational horizontal self-construal, collective horizontal selfconstrual, collective vertical self-construal, humanistic self-construal, and personal self-construalaffect teachers' job satisfaction in a collectivist cultural context. Our research questions were the following:

1. Do dimensions of self-construal (relational vertical self, relational horizontal self, collective horizontal self, collective vertical self, humanistic self, and personal self) predict teachers' intrinsic satisfaction?

2. Do dimensions of self-construal (relational vertical self, relational horizontal self, collective horizontal self, collective vertical self, humanistic self, and personal self) predict teachers' extrinsic satisfaction?

3. Do dimensions of self-construal (relational vertical self, relational horizontal self, collective horizontal self, collective vertical self, humanistic self, and personal self) predict teachers' job satisfaction (total)?

To examine possible cultural variations in job satisfaction due to different dimensions of selfconstrual (vertical relational, horizontal relational, vertical collective, horizontal collective, humanistic, and personal self-construal), we questioned the possibility of whether self-construal's different dimensions would produce relationships with intrinsic, extrinsic, and job satisfaction (total). In the study, understanding how teachers' self-construal combines with their job satisfaction might help in the development of a culturally sensitive school environment for fostering and maintaining teachers' job satisfaction.

\section{Method}

The current research was a correlational study. A correlational study is a research design in which the researcher seeks to understand the kinds of naturally occurring variables related to each other (Fraenkel et al., 2012). The study's criterion variables were the teacher extrinsic, intrinsic, and job satisfaction (total). Six dimensions of self-construal-vertical relational, horizontal relational, vertical collective, horizontal collective, humanistic, and personal self-construal-were the predictor variables.

\subsection{Participants and Procedure}

Participants in the current study were 426 of 1717 teachers from 51 schools - primary, secondary, and high schools (1st-12th grades) - in a mid-sized city in Turkey. The city had a population of about 133,000 inhabitants. The age ranged from 23 to $62 ; 48.0 \%(n=204)$ of the sample was female and $47.5 \%(n=202)$ of the sample was male, while for $4.5 \%(n=19)$, the participants' gender was not mentioned. In this study, the purposive sampling method was used to select participants. Participants were recruited via visits to schools in the seminar period, the last two weeks of June. Participation involved the completion of a battery of questionnaires measuring job satisfaction and self-construal. In each school, we assigned a certain amount of time for all teachers to answer the scales. The study participants consisted of teachers who were at the school at the time of data collection and who agreed to participate in the study. 


\subsection{Instruments}

\subsubsection{Minnesota Satisfaction Questionnaire}

The Minnesota Satisfaction Questionnaire (MSQ) is one of the most extensively used tools for measuring job satisfaction. Weiss et al. (1967) developed the MSQ with two forms: the long form and the short form. In this study, the short form was used. The short form of the MSQ consists of 20 items that measure different aspects of job satisfaction (Spector, 1997). The MSQ consists of 20 items and two sub-scales. It can be scored to provide a single index of Overall Job Satisfaction (total) or separate Intrinsic and Extrinsic Job Satisfaction indices. Baycan (1985) adapted MSQ to Turkish culture. The MSQ was used in this study to measure specific aspects and total job satisfaction with regard to a teacher's satisfaction with his/her job.

\subsubsection{Sixfold Self-Construal Scale}

The Sixfold Self-Construal Scale (SSCS) (Harb \& Smith, 2008) consists of six dimensions of selfconstrual: relational vertical, relational horizontal, collective vertical, collective horizontal, humanistic, and personal self. Participants rated the degree to which they agreed with each item on a 7 Likert scale, from 1 (to a very small extent) to 7 (to a very large extent). Harb and Smith (2008) conducted a confirmatory factor analysis of the SSCS in samples of British, Lebanese, Syrian, and Jordanian university students. A six-factor model fits the data well, and the values of each subscale gave sufficient Cronbach's Alpha reliability ( $\alpha=.68-.92)$ (Harb \& Smith, 2008).

Özcan and Ögüulmüş (2021) adapted the SSCS to Turkish culture with the 330 participants. Confirmatory Factor Analysis (CFA) findings showed that $\chi 2 / s d=2.95$, RMSEA $=.07, \mathrm{CFI}=.93$, $\mathrm{NNFI}=.92$, and SRMR $=.05$. In the reliability study, the Cronbach's Alpha coefficient was $a=.73$ for relational vertical self-construal, and the values for other dimensions of self-construal were above $a=.80$. To test the stability of the scale, the test-retest reliability coefficient calculated for each dimension was between $r=.70$ and $r=.82$ (Özcan \& Öğülmüş, 2021). In this study, we used Harb and Smith's (2008) Sixfold Self-Construal Scale (SSCS), measuring six dimensions of selfconstrual, because it has sufficient reliability and validity in collectivist countries.

\subsection{Data Analysis}

We conducted a stepwise multiple linear regression analysis with the SPSS 23 program. The stepwise multiple regression analysis was run to predict intrinsic, extrinsic, and job satisfaction (total) from six dimensions of self-construal: relational vertical self-construal, relational horizontal self-construal, collective horizontal self-construal, collective vertical self-construal, humanistic selfconstrual, and personal self-construal. The variables in the regression analysis are normally distributed according to skewness and kurtosis values ranging between -1 and +1 . Multicollinearity was measured by variance inflation factors (VIF). VIF values of the predictors ranged from 1.12 to 2.22 . If the VIF value exceeding 4 , then there is a multicollinearity problem (Hair et al., 2010). There is no collinearity problem between dependent variables in this study.

\section{Results}

\subsection{Correlation between Variables}

The relationship between teachers' scores obtained from the six dimensions of self-construal (relational vertical self-construal, relational horizontal self-construal, collective horizontal selfconstrual, collective vertical self-construal, humanistic self-construal, and personal self-construal) and intrinsic satisfaction, extrinsic satisfaction, and job satisfaction (total) scores was investigated. Descriptive statistics related to means, standard deviations, and correlation values of variables entering into regression equality are presented in Table 1. 
Table 1

Descriptive statistics and correlations related to predictors and criterion variables

\begin{tabular}{llllllllll}
\hline Variables & 1 & 2 & 3 & 4 & 5 & 6 & 7 & 8 & 9 \\
\hline Self-construal & & & & & & & & & \\
Relational vertical self(1) & 1.00 & & & & & & & & \\
Relational horizontal self(2) & $.63^{* *}$ & 1.00 & & & & & & & \\
Collective horizontal self(3) & $.49^{* *}$ & $.71^{* *}$ & 1.00 & & & & & & \\
Collective vertical self(4) & $.32^{* *}$ & $.61^{* *}$ & $.67^{* *}$ & 1.00 & & & & & \\
Humanistic self(5) & $.41^{* *}$ & $.61^{* *}$ & $.62^{* *}$ & $.63^{* *}$ & 1.00 & & & & \\
Personal self(6) & $.32^{* *}$ & $.33^{* *}$ & $.35^{* *}$ & $.37^{* *}$ & $.43^{* *}$ & 1.00 & & & \\
Job satisfaction & & & & & & & & & \\
Intrinsic satisfaction(7) & $.24^{* *}$ & $.26^{* *}$ & $.28^{* *}$ & $.22^{* *}$ & $.26^{* *}$ & $.24^{* *}$ & 1.00 & & \\
Extrinsic satisfaction(8) & $.19^{* *}$ & $.29^{* *}$ & $.41^{* *}$ & $.30^{* *}$ & $.34^{* *}$ & $.22^{* *}$ & $.62^{* *}$ & 1.00 & \\
Job satisfaction (Total)(9) & $.24^{* *}$ & $.30^{* *}$ & $.38^{* *}$ & $.28^{* *}$ & $.33^{* *}$ & $.26^{* *}$ & $.91^{* *}$ & $.89^{* *}$ & 1.00 \\
$M$ & 30.69 & 27.57 & 25.63 & 25.56 & 26.49 & 25.89 & 48.61 & 28.56 & 77.17 \\
SD & 4.34 & 4.91 & 5.75 & 6.07 & 5.55 & 5.66 & 5.97 & 5.33 & 10.16 \\
\hline
\end{tabular}

Note. $N=426,{ }^{*} p<.05,{ }^{* *} p<.001$

As seen in Table 1, there were significant positive but weak correlations between intrinsic satisfaction and collective horizontal self-construal $(r=.28, p<.001)$, humanistic self-construal $(r=.26, p<.001)$, relational horizontal self-construal $(r=.26, p<.001)$, relational vertical selfconstrual $(r=.24, p<.001)$, personal self-construal $(r=.24, p<.001)$, and collective vertical selfconstrual $(r=.22, p<.001)$. These findings indicated that as teachers' intrinsic satisfaction increased, their collective horizontal self, humanistic self, relational horizontal self, relational vertical self, personal self, and collective vertical self increased as well.

In addition, there was a significant moderate positive correlation between extrinsic satisfaction and collective horizontal self-construal $(r=.41, p<.001)$ and significant positive but weak correlations between extrinsic satisfaction and humanistic self-construal $(r=.34, p<.001)$, collective vertical self-construal $(r=.30, p<.001)$, relational horizontal self-construal $(r=.29$, $p<.001)$, personal self-construal $(r=.22, p<.001)$, and relational vertical self-construal $(r=.19$, $p<.001)$. These findings suggest that as teachers' extrinsic satisfaction increased, their collective horizontal self-construal, humanistic self-construal, collective vertical self-construal, relational horizontal self-construal, personal self-construal, and relational vertical self-construal increased as well.

Lastly, there were significant positive but weak correlations between job satisfaction (total) and collective horizontal self-construal $(r=.38, p<.001)$, humanistic self-construal $(r=.33, p<.001)$, relational horizontal self-construal $(r=.30, p<.001)$, collective vertical self-construal $(r=.28$, $p<.001)$, personal self-construal $(r=.26, p<.001)$, and relational vertical self-construal $(r=.24$, $p<.001)$. The findings indicated that as teachers' job satisfaction increased, their self-construal (collective horizontal, humanistic, relational horizontal, collective vertical, personal, and relational vertical) increased as well.

\subsection{Predicting Intrinsic Satisfaction from Self-construal}

Stepwise multiple regression was run to determine whether the addition of six dimensions of selfconstrual (relational vertical self-construal, relational horizontal self-construal, collective horizontal self-construal, collective vertical self-construal, humanistic self-construal, and personal self-construal) obtained from a submaximal test improved the prediction of intrinsic satisfaction. See Table 2 for full details on each regression model.

There was an independence of residuals, as assessed by a Durbin-Watson statistic of 2.061. There was no evidence of multicollinearity, as assessed by tolerance values greater than 0.1 . If the tolerance value is less than 0.1 , there might be a collinearity problem (Hair et al., 2014). In this analysis, all the tolerance values are higher than 0.1 (the lowest is 0.730 ). Five residuals were treated as outliers by using the Casewise Diagnostics value of greater than \pm 3 cut-off criteria. 
Table 2

Stepwise multiple regression predicting intrinsic satisfaction from self-construal

\begin{tabular}{lcccccc}
\hline \multirow{2}{*}{ Predictors } & \multicolumn{2}{c}{ Model 1 } & \multicolumn{2}{c}{ Model 2 } & \multicolumn{2}{c}{ Model 3 } \\
\cline { 2 - 7 } & $B$ & $\beta$ & $B$ & $\beta$ & 3 & $\beta$ \\
\hline Constant & $37.580^{* *}$ & & $35.659^{* *}$ & & $34.557^{* *}$ & \\
$\quad$ Relational vertical self & $.367^{* *}$ & .284 & $.267^{* *}$ & .206 & $.239^{* *}$ & .185 \\
Humanistic self & - & .186 & $.188^{* *}$ & .186 & $.144^{*}$ & .142 \\
Personal self & - & .170 & - & .122 & $.121^{*}$ & .122 \\
Collective horizontal self & - & .149 & - & .064 & - & .055 \\
Collective vertical self & - & .132 & - & .044 & - & .027 \\
$\quad$ Relational horizontal self & - & .129 & - & .026 & - & .027 \\
$R^{2}$ & .080 & & .109 & & .121 & \\
$F$ & $36.626^{* *}$ & & $25.581^{* *}$ & & $19.103^{* *}$ & \\
$\Delta R^{2}$ & .078 & & .029 & & .012 & \\
$\Delta F$ & $36.626^{* *}$ & & $13.448^{* *}$ & & $5.586^{*}$ & \\
\hline
\end{tabular}

Note. $N=421,{ }^{*} p>.05,{ }^{* *} p>.001$

The full model of the six dimensions of self-construal (relational vertical self-construal, relational horizontal self-construal, collective horizontal self-construal, collective vertical selfconstrual, humanistic self-construal, and personal self-construal) to predict intrinsic satisfaction (Model 3) was statistically significant, $R^{2}=.121, F(3,417)=19.103, p<.001$; adjusted $R^{2}=.115$. This finding indicated that relational vertical self-construal, relational horizontal self-construal, collective horizontal self-construal, collective vertical self-construal, humanistic self-construal, and personal self-construal explained $12 \%$ of the total variance related to intrinsic satisfaction. The relative order of significance among predictor variables on job satisfaction according to the standardized regression coefficient $(\beta)$ included relational vertical self $(\beta=.19)$, humanistic self $(\beta=.14)$, and personal self $(\beta=.12)$, respectively. Moreover, the addition of the humanistic self to the prediction of intrinsic satisfaction (Model 2) led to a statistically significant increase in $R^{2}$ of $.029, F(1,418)=13.448, p<.001$. The addition of personal self to the prediction of intrinsic satisfaction (Model 3) also led to a statistically significant increase in $R^{2}$ of .012, $F(1,417)=5.586, p<.05$. On the other hand, relational horizontal self, collective horizontal self, and collective vertical self were not significant predictors of intrinsic satisfaction (see Table 2).

\subsection{Predicting Extrinsic Satisfaction from Self-construal}

Stepwise multiple linear regression was run to determine whether the addition of the six dimensions of self-construal obtained from a submaximal test improved the prediction of extrinsic satisfaction. See Table 3 for full details on each regression model. There was an independence of residuals, as assessed by a Durbin-Watson statistic of 2.053 . There was no evidence of multicollinearity, as assessed by tolerance values greater than 0.1 . If the tolerance value is less than 0.1 , there might be a collinearity problem (Hair et al., 2014). In this analysis, all the tolerance values are higher than 0.1 (the lowest is 0.620 ). Three residuals were treated as outliers by using the Casewise Diagnostics value of greater than \pm 3 cut-off criteria.

The full model of relational vertical self-construal, relational horizontal self-construal, collective horizontal self-construal, collective vertical self-construal, humanistic self construal, and personal self-construal to predict extrinsic satisfaction (Model 2) was statistically significant, $R^{2}=.202$, $F(2,420)=53.025, p<.001$; adjusted $R^{2}=.198$. The finding suggested that the six dimensions of self-construal explained $20 \%$ of the total variance related to extrinsic satisfaction. The relative order of significance among predictor variables on extrinsic satisfaction according to the standardized regression coefficient $(\beta)$ included collective horizontal self $(\beta=.35)$ and humanistic self $(\beta=.14)$, respectively. The addition of humanistic self to the prediction of extrinsic satisfaction (Model 2) led 
Table 3

Stepwise multiple regression predicting extrinsic satisfaction from self-construal

\begin{tabular}{lcccc}
\hline \multirow{2}{*}{ Predictors } & \multicolumn{2}{c}{ Model 1 } & $\beta$ & \multicolumn{2}{c}{ Model 2 } \\
\cline { 2 - 5 } & $B$ & & $17.033^{* *}$ & $\beta$ \\
\hline Constant & $18.545^{* *}$ & .435 & $.315^{* *}$ & .346 \\
$\quad$ Collective horizontal self & $.395^{* *}$ & .143 & $.135^{*}$ & .143 \\
Humanistic self & - & .109 & - & .081 \\
Personal self & - & .035 & - & -.024 \\
Collective vertical self & - & -.017 & - & -.040 \\
Relational vertical self & - & .005 & - & -.050 \\
$\quad$ Relational horizontal self & - & & .202 & \\
$R^{2}$ & .189 & & $53.025^{* *}$ & \\
$F$ & $98.045^{* *}$ & .013 & \\
$\Delta R^{2}$ & .189 & & $6.682^{*}$ & \\
$\Delta F$ & $98.045^{* *}$ & & &
\end{tabular}

Note. $N=423,{ }^{*} p>.05,{ }^{* *} p>.001$

to a statistically significant increase in $R^{2}$ of $.013, F(1,420)=6.682, p<.05$. On the other hand, relational horizontal self, relational vertical self, collective vertical self, and personal self were not significant predictors of extrinsic satisfaction.

\subsection{Predicting Job Satisfaction (Total) from Self-construal}

Stepwise multiple regression was run to determine whether the addition of relational vertical selfconstrual, relational horizontal self-construal, collective horizontal self-construal, collective vertical self-construal, humanistic self-construal, and personal self-construal obtained from a submaximal test improved the prediction of job satisfaction (total). See Table 4 for full details on each regression model.

There was an independence of residuals, as assessed by a Durbin-Watson statistic of 2.071. There was no evidence of multicollinearity, as assessed by tolerance values greater than 0.1 . If the tolerance value is less than 0.1, there might be a collinearity problem (Hair et al., 2014). In this analysis, all the tolerance values are higher than 0.1 (the lowest is 0.566 ). One residual was treated as an outlier by using the Casewise Diagnostics value of greater than \pm 3 cut-off criteria.

Table 4

Stepwise multiple regression predicting intrinsic satisfaction from self-construal

\begin{tabular}{|c|c|c|c|c|c|c|}
\hline \multirow[b]{2}{*}{ Predictors } & \multicolumn{2}{|c|}{ Model 1} & \multicolumn{2}{|c|}{ Model 2} & \multicolumn{2}{|c|}{ Model 3} \\
\hline & $B$ & $\beta$ & $B$ & $\beta$ & $B$ & $\beta$ \\
\hline Constant & $60.035^{\star *}$ & & $56.725^{\star *}$ & & $54.299 * *$ & \\
\hline Collective horizontal self & $.672^{* *}$ & .385 & $.497^{* *}$ & .284 & $.473^{\star *}$ & .271 \\
\hline Humanistic self & - & .163 & $.294^{* *}$ & .163 & $.228^{*}$ & .126 \\
\hline Personal self & - & .135 & - & .104 & $.185^{*}$ & .104 \\
\hline Collective vertical self & - & .049 & - & -.017 & - & -.029 \\
\hline Relational vertical self & - & .084 & - & .061 & - & .046 \\
\hline Relational horizontal self & - & .065 & - & .008 & - & .002 \\
\hline$R^{2}$ & 148 & & .164 & & 173 & \\
\hline$F$ & $73.488^{* *}$ & & $41.519^{* *}$ & & $29.384^{* *}$ & \\
\hline$\Delta R^{2}$ & .148 & & .016 & & .009 & \\
\hline$\Delta F$ & $73.488^{* *}$ & & $8.284^{*}$ & & $4.439 *$ & \\
\hline
\end{tabular}

Note. $N=421, * p>.05, * * p>.001$

The full model of the six dimensions of self-construal to predict job satisfaction (Model 3) was statistically significant, $R^{2}=.173, F(3,421)=29.384, p<.001$; adjusted $R^{2}=.167$. The finding showed that relational vertical self-construal, relational horizontal self-construal, collective horizontal self-construal, collective vertical self-construal, humanistic self-construal, and personal 
self-construal explained $17 \%$ of the total variance related to teacher job satisfaction. The relative order of significance among predictor variables on job satisfaction according to the standardized regression coefficient $(\beta)$ included collective horizontal self $(\beta=.27)$, humanistic self $(\beta=.13)$, and personal self $(\beta=.10)$, respectively. The addition of humanistic self to the prediction of job satisfaction (Model 2) led to a statistically significant increase in $R^{2}$ of $.016, F(1,422)=8.284, p<.01$. Lastly, the addition of personal self to the prediction of job satisfaction (Model 3) also led to a statistically significant increase in $R^{2}$ of $.009, F(1,421)=4.439, p<.05$. On the other hand, relational horizontal self, relational vertical self, and collective vertical self were not significant predictors of job satisfaction.

\section{Discussion and Conclusion}

This study's unique feature was the addition of self-construal to capture aspects of Turkish teachers' job satisfaction in a collective cultural context. We had anticipated that the four dimensions of self-construal would reflect a group-focused cultural identification, one dimension of self-construal would reflect a humanity-bound cultural identification, and the last dimension would represent a more independent cultural stance. The findings indicated that relational vertical, humanistic, and personal self-construal significantly predicted intrinsic satisfaction. Moreover, collective horizontal and humanistic self-construal significantly predicted extrinsic satisfaction. Lastly, collective horizontal, humanistic, and personal self-construal significantly predicted job satisfaction (total).

This research revealed the relationship between culture and job satisfaction in a collectivistic cultural context. It contributed to the exploration of the effect of self-construal, in the context of social relations, on an individual's job satisfaction. In keeping with other studies that have added culture-specific variables to some satisfaction models (Hui et al., 2013; Sheu et al., 2014), these findings suggest that certain dimensions of self-construal are related to teacher intrinsic, extrinsic, and job satisfaction.

The relational vertical self significantly predicted only intrinsic satisfaction and did not significantly predict extrinsic and job satisfaction. Moreover, horizontal self-construal was the most powerful predictor of intrinsic satisfaction. The relational vertical self includes close hierarchical relationships, and it is experienced in the family context. Teachers' family relationships have a strong influence on their intrinsic satisfaction. The fact that Turkish culture is a collective culture (Hofstede et al., 2010) and that Turkish culture assigns special importance to family relationships (Kağıtçıbaş1, 2017; Uskul et al., 2004) supported the findings of this study. The teacher might have perceived intrinsic satisfaction in relation to his/her relational vertical self rather than personal self. While intrinsic satisfaction would be expected to be associated with personal self-construal in an individualistic society, it was associated with the relational vertical self in Turkish culture. Therefore, the relational vertical self emerged as the strongest predictor of intrinsic satisfaction. We suggested to teachers and administrators to evaluate the high and low levels of intrinsic satisfaction in the context of family relationships. Teachers who have dysfunctional family relationships and low intrinsic satisfaction should have family therapy.

Intrinsic satisfaction is a personal process; thus, it is expected that the personal self, which expresses the self-construal individual dimension, would affect intrinsic satisfaction. The individual evaluated intrinsic satisfaction according to his or her internal standards. The humanistic self affects teachers' intrinsic, extrinsic, and job satisfaction because the teaching profession generally emphasizes humanistic values. The government and Ministry of education should improve educational programs to emphasize humanistic values more. Administrators and teachers should organize the school context to teach humanistic values to students.

In particular, consistent with expectations, collective horizontal self-construal was linked to extrinsic satisfaction, suggesting that teachers adhering to collective horizontal relations were more likely to perceive as part of their extrinsic and total job satisfaction. The collective horizontal self manifests itself in the context of teachers' relationships with their colleagues in school settings. It 
was the strongest predictor of both extrinsic and job satisfaction (total). Teachers' higher satisfaction with their relationships with each other positively affected teachers' extrinsic and job satisfaction (total). This finding could be explained by the fact that Turkish culture is a collective culture (Hofstede et al., 2010), and it is crucial to establish harmonious relationships in the individual's environment. The importance of harmonious relationships in nearby environments affects the individual's job satisfaction in the school context. Researchers emphasized the importance of relationships between colleagues in terms of job satisfaction (Cockburn \& Haydn, 2004; Huang \& Van de Vliert, 2004; Mottaz, 1985; Robbins, 1996; Warr, 2007; Vroom, 1982; Yetim \& Yetim, 2006), consistent with the current study's findings. According to these findings, especially in collective cultures, educational institutions should arrange environments and time zones so that teachers can have social relationships with each other. In this way, educational institutions contribute to teachers' job satisfaction, and this increase in job satisfaction positively affects teachers' professional performance.

Individualistic societies are expected to show different relationships between teachers' selfconstrual and job satisfaction. This research should be carried out in individualistic cultural contexts. In the individualistic culture, different dimensions of self-construal may predict job satisfaction, and the predictive power of self-construal may vary compared to that in collective cultures. The relationship between self-construal and job satisfaction can also be examined in different occupational groups.

In conclusion, this study provides an empirical test of the relationship between the six dimensions of self-construal and teacher job satisfaction in the collective cultural context. The results contribute to an understanding of self-construal that may facilitate teacher job satisfaction in a collective culture. Specifically, relational vertical, personal, and humanistic self-construal are associated with teacher intrinsic satisfaction; collective horizontal and humanistic self-construal are associated with extrinsic satisfaction; and collective horizontal, personal, and humanistic selfconstrual are associated with job satisfaction (total) in our sample. These findings may inform school administrators about the school climate's development that gives teachers more chances to cooperate and establish relationships to increase their job satisfaction.

\section{References}

Admiraal, W., Veldman, I., Mainhard, T., \& van Tartwijk, J. (2019). A typology of veteran teachers' job satisfaction: Their relationships with their students and the nature of their work. Social Psychology of Education, 22(2), 337-355. https:/ / doi.org/10.1007/s11218-018-09477-z

Alderman, K. M. (2004). Motivation for achievement: Possibilities for teaching and learning. Lawrence Erlbaum Associates, Inc.

Atchison, T. A. (1999). The myths of employee satisfaction. Healthcare Executive, 14(2), 18-23.

Ayan, S., \& Kocacik, F. (2010). The relation between the level of job satisfaction and types of personality in high school teachers. Australian Journal of Teacher Education, 35(1), 27-41. http:/ / dx.doi.org/10.14221/ajte.2010v35n1.4

Baycan, F. A. (1985). Analysis of some aspects of job satisfaction in people working in different groups (Unpublished doctoral dissertation). Bogazici University, Istanbul.

Bogler, R. (2001). The influence of leadership style on teacher job satisfaction. Educational Administration Quarterly, 37(5), 662-683. https://doi.org/10.1177/00131610121969460

Brouwers, A., \& Tomic, W. (2000). A longitudinal study of teacher burnout and perceived self-efficacy in classroom management. Teaching and Teacher Education, 16(2), 239-253. https://doi.org/10.1016/S0742051X(99)00057-8

Buitendach, J. H., \& De Witte, H. (2005). Job insecurity, extrinsic and intrinsic job satisfaction and affective organisational commitment of maintenance workers in a parastatal. South African Journal of Business Management, 36(2), 27-38. http:/ /dx.doi.org/10.4102/sajbm.v36i2.625

Caprara, G. V., Barbaranelli, C., Borgogni, L., \& Steca, P. (2003). Efficacy beliefs as determinants of teachers' job satisfaction. Journal of Educational Psychology, 95(4), 821-832. https://doi.org/10.1037/00220663.95.4.821 
Caprara, G. V., Barbaranelli, C., Steca, P., \& Malone, P. S. (2006). Teachers' self-efficacy beliefs as determinants of job satisfaction and students' academic achievement: A study at the school level. Journal of School Psychology, 44(6), 473-490. https:// doi.org/10.1016/j.jsp.2006.09.001

Chen, J. (2010). Chinese middle school teacher job satisfaction and its relationships with teacher moving. Asia Pacific Education Review, 11(3), 263-272. https:// doi.org/10.1007/s12564-010-9085-1

Cheng, C., Cheung, M. W. L., Montasem, A., Awang-Hashim, R., Bacova, V., Baumane, I., Chan, R., Christou, M., Chun, W. Y., Clemena, R. M., Comunian, A. L., Czapinski, J., Dayan, N., Loving, R. D., Duarte-Silva, M. E., Falzon, A., Falzon, R., Gan, Y., Golden, D. L., ... Uglanova, E. (2016). Explaining differences in subjective well-being across 33 nations using multilevel models: Universal personality, cultural relativity, and national income. Journal of Personality, 84(1), 46-58. https://doi.org/10.1111/jopy.12136

Cheng, C., Jose, P. E., Sheldon, K. M., Singelis, T. M., Cheung, M. W., Tiliouine, H., Alao, A. A., Chio, J. H. M., Lui, J. Y. M., Chun, W. Y., de Zavala, A.G., Hakuzimana, A., Hertel. J., Liu, J., Onyewadume, M., \& Sims, C. (2011). Sociocultural differences in self-construal and subjective well-being: A test of four cultural models. Journal of Cross-Cultural Psychology, 42(5), 832-855. https://doi.org/10.1177/0022022110381117

Christopher, M. S., D'Souza, J. B., Peraza, J., \& Dhaliwal, S. (2010). A test of the personality-culture clash hypothesis among college students in an individualistic and collectivistic culture. International Journal of Culture and Mental Health, 3(2), 107-116. https:/ / doi.org/10.1080/17542863.2010.491707

Cockburn, A. D., \& Haydn, T. (2004). Recruiting and retaining teachers: Understanding why teachers teach. Routledge Falmer.

Dickson, K. E., \& Lorenz, A. (2009). Psychological empowerment and job satisfaction of temporary and parttime nonstandard workers: A preliminary investigation. Journal of Behavioral and Applied Management, 10(2), 166-191.

Dinham, S., \& Scott, C. (1998). A three domain model of teacher and school executive career satisfaction. Journal of Educational Administration, 36 36 (4), https://doi.org/10.1108/09578239810211545

Duncan, E., Ornaghi, V., \& Grazzani, I. (2013). Self-construal and psychological wellbeing in Scottish and Italian young adults. Journal of Happiness Studies, 14(4), 1145-1161. https://doi.org/10.1007/s10902-0129372-0

Elizabeth G, \& Zakkariya, K. A. (2018). Psychological empowerment and job satisfaction in the banking sector. Palgrave Pivot.

Fiske, S. T., \& Taylor, S. E. (1991). McGraw-Hill series in social psychology. Social cognition (2nd ed.). McGrawHill.

Fraenkel, J., Wallen, N., \& Hyun, H. H. (2012). How to design and evaluate research in education (8th ed.). McGraw-Hill.

Gelfand, M. J., Nishii, L. H., \& Raver, J. L. (2006). On the nature and importance of cultural tightnesslooseness. Journal of Applied Psychology, 91(6), 1225-1244. https://doi.org/10.1037/0021-9010.91.6.1225

Greenglass, E. R., \& Burke, R. J. (2003). Teacher stress. In M. F. Dollard, A. H. Winefield, \& H. R. Winefield (Eds.), Occupational stress in the service professions (pp. 213-236). Taylor \&Francis.

Haberstroh, S., Oyserman, D., Schwarz, N., Kühnen, U., \& Ji, L. J. (2002). Is the interdependent self more sensitive to question context than the independent self? Self-construal and the observation of conversational norms. Journal of Experimental Social Psychology, 38(3), 323-329. https://doi.org/10.1006/jesp.2001.1513

Hackman, J. R., \& Oldham, G. R. (1976). Motivation through the design of work: Test of a theory. Organizational Behavior and Human Performance, 16(2), 250-279. https://doi.org/10.1016/00305073(76)90016-7

Hair, J. F., Black, W. C., Babin, B. J., \& Anderson, R. E. (2014). Multivariate data analysis (7th ed.). Pearson Education Limited.

Harb, C., \& Smith, P. B. (2008). Self-construals across cultures: Beyond independence-interdependence. Journal of Cross-Cultural Psychology, 39(2), 178-198. https:// doi.org/10.1177/0022022107313861

Herzberg, F. (1987). One more time: How do you motivate employees? Harvard Business Review, 65(5), 109120.

Herzberg, F., Mausner, B., \& Snyderman, B. (2010). The motivation to work (12th ed.). Transaction Publishers.

Hofstede, G. (1980). Culture and organizations. International Studies of Management \& Organization, 10(4), 1541. https://doi.org/10.1080/00208825.1980.11656300 
Hofstede, G., Hofstede G. J., \& Minkov, M. (2010). Organizations and cultures: Software of the mind (3rd ed.). McGraw-Hill.

Hongying, S. (2007). Literature review of teacher job satisfaction. Chinese Education \& Society, 40(5), 11-16. https://doi.org/10.2753/CED1061-1932400502

Huang, X., \& Van de Vliert, E. (2004). Job levels and national culture as joint roots of job satisfaction. Applied Psychology: An International Review, 53(3), 329-348. https:// doi.org/10.1111/j.1464-0597.2004.00174.x

Hui, C. H., \& Yee, C. (1999). The impact of psychological collectivism and workgroup atmosphere on Chinese employees' job satisfaction. Applied Psychology: An International Review, 48(2), 175-185.

Ingersoll, R. M. (2001). Teacher turnover and teacher shortages: An organizational analysis. American Educational Research Journal, 38(3), 499-534. https://doi.org/10.3102/00028312038003499

Judge, T. A., \& Bono, J. E. (2001). Relationship of core self-evaluations traits - self-esteem, generalized selfefficacy, locus of control, and emotional stability - with job satisfaction and job performance: A metaanalysis. Journal of Applied Psychology, 86(1), 80-92. https://doi.org/10.1037//0021-9010.86.1.80

Judge, T. A., Thoresen, C. J., Bono, J. E., \& Patton, G. K. (2001). The job satisfaction-job performance relationship: A qualitative and quantitative review. Psychological Bulletin, 127(3), 376-407. https:// doi.org/10.1037/0033-2909.127.3.376

Kağıtçıbaşı, Ç. (2017). Family, self, and human development across cultures: Theory and applications. Taylor \& Francis.

Kemelgor, B. H. (1982). Job satisfaction as mediated by the value congruity of supervisors and their subordinates. Journal of Occupational Behaviour, 3(2), 147-160. https://doi.org/10.1002/job.4030030202

Kirkman, B. L., \& Shapiro, D. L. (2001). The impact of cultural values on job satisfaction and organizational commitment in self-managing work teams: The mediating role of employee resistance. Academy of Management Journal, 44(3), 557-569. https:// doi.org/10.5465/3069370

Kunter, M., Klusmann, U., Baumert, J., Richter, D., Voss, T., \& Hachfeld, A. (2013). Professional competence of teachers: Effects on instructional quality and student development. Journal of Educational Psychology, 105(3), 805-820. https://doi.org/10.1037/a0032583

Kwantes, C. T. (2010). The facets of job satisfaction: A nine-nation comparative study of construct equivalence. Applied Multivariate Research, 13(2), 145-159. https://doi.org/10.22329/amr.v13i2

Lawler, E. (1990). Strategic pay: Aligning organizational strategies and pay systems. Jossey-Bass.

Li, M., \& Wang, Z. (2016). Emotional labour strategies as mediators of the relationship between public service motivation and job satisfaction in Chinese teachers. International Journal of Psychology, 51(3), 177184. https:// doi.org/10.1002/ijop.12114

Locke, E. A. (1976). The nature and causes of job satisfaction. In M. D. Dunnette (Ed.), Handbook of industrial and organizational psychology (pp. 1297-1349). Rand McNally.

Markus, H. R., \& Kitayama, S. (1991). Culture and the self: Implications for cognition, emotion, and motivation. Psychological Review, 98(2), 224-253. https://doi.org/10.1037/0033-295X.98.2.224

Maulana, H., Khawaja, N., \& Obst, P. (2021). An Indonesian model of well-being: The integration of universal and cultural factors. PsyCh Journal, 10(1), 141-154. https:// doi.org/10.1002/ pchj.402

Moses, I., Berry, A., Saab, N., \& Admiraal, W. (2017). Who wants to become a teacher? Typology of studentteachers' commitment to teaching. Journal of Education for Teaching, 43(4), 444-457. https:// doi.org/10.1080/02607476.2017.1296562

Mottaz, C. J. (1985). The relative importance of intrinsic and extrinsic rewards as determinants of work satisfaction. The Sociological Quarterly, 26(3), 365-385. https://doi.org/10.1111/j.1533-8525.1985.tb00233.x

Moza, D., Lawrie, S. I., Maricuțoiu, L., Gavreliuc, A., \& Kim, H. S. (2020). Not all forms of independence are created equal: Only being independent the "Right Way" is associated with self-esteem and life satisfaction. Frontiers in Psychology, 11, 606354. https:/ / doi.org/10.3389/fpsyg.2020.606354

Novin, S., Tso, I. F., \& Konrath, S. H. (2014). Self-related and other-related pathways to subjective well-being in Japan and the United States. Journal of Happiness Studies, 15(5), 995-1014. https://doi.org/10.1007/s10902-013-9460-9

Oyserman, D., Bybee, D., Terry, K., \& Hart-Johnson, T. (2004). Possible selves as roadmaps. Journal of Research in Personality, 38(2), 130-149. https:/ / doi.org/10.1016/S0092-6566(03)00057-6

Özcan, B. (2017). Predictors of subjective well being: self construal self esteem and social support (Unpublished doctoral dissertation). Ankara University, Ankara.

Özcan, B., \& Öğülmüş, S. (2021). Adaptation of the sixfold self-construal scale to Turkish culture. SDU Faculty of Arts And Sciences Journal Of Social Sciences, 52, 41-56. 
Park, J., Norasakkunkit, V., \& Kashima, Y. (2017). Cross-cultural comparison of self-construal and well-being between Japan and South Korea: the role of self-focused and other-focused relational selves. Frontiers in Psychology, 8, 1516. https:/ / doi.org/10.3389/fpsyg.2017.01516

Pepe, A., Addimando, L., \& Veronese, G. (2017). Measuring teacher job satisfaction: Assessing invariance in the teacher job satisfaction scale (TJSS) across six countries. Europe's Journal of Psychology, 13(3), 396-416. https://doi.org/10.5964/ejop.v13i3.1389

Reyes, P., \& Shin, H. S. (1995). Teacher commitment and job satisfaction: A causal analysis. Journal of School Leadership, 5(1), 22-39. https://doi.org/10.1177/105268469500500102

Riketta, M. (2008). The causal relation between job attitudes and performance: A meta-analysis of panel studies. Journal of Applied Psychology, 93(2), 472-481. https:/ / doi.org/10.1037/0021-9010.93.2.472

Robbins, S.P. (1996). Organizational behavior: Concepts, controversies, and applications (7th ed.). Prentice Hall.

Schaufeli, W. B., \& Salanova, M. (2007). Efficacy or inefficacy, that's the question: Burnout and work engagement, and their relationships with efficacy beliefs. Anxiety, Stress, and Coping, 20(2), 177-196. https://doi.org/10.1080/10615800701217878

Sheu, H. B., Chong, S. S., Chen, H. F., \& Lin, W. C. (2014). Well-being of Taiwanese and Singaporean college students: Cross-cultural validity of a modified social cognitive model. Journal of Counseling Psychology, 61(3), 447-460. https:/ / doi.org/10.1037/cou0000018

Shoshani, A., \& Eldor, L. (2016). The informal learning of teachers: Learning climate, job satisfaction and teachers' and students' motivation and well-being. International Journal of Educational Research, 79, 52-63. https://doi.org/10.1016/j.ijer.2016.06.007

Singelis, T. M. (1994). The measurement of independent and interdependent self-construals. Personality and Social Psychology Bulletin, 20(5), 580-591. https:/ / doi.org/10.1177/0146167294205014

Skaalvik, E. M., \& Skaalvik, S. (2010). Teacher self-efficacy and teacher burnout: A study of relations. Teaching and Teacher Education, 26(4), 1059-1069. https:/ / doi.org/10.1016/j.tate.2009.11.001

Skaalvik, E. M., \& Skaalvik, S. (2011). Teacher job satisfaction and motivation to leave the teaching profession: Relations with school context, feeling of belonging, and emotional exhaustion. Teaching and Teacher Education, 27(6), 1029-1038. https:/ / doi.org/10.1016/j.tate.2011.04.001

Skaalvik, E. M., \& Skaalvik, S. (2014). Teacher self-efficacy and perceived autonomy: Relations with teacher engagement, job satisfaction, and emotional exhaustion. Psychological reports, 114(1), 68-77. https:/ / doi.org/10.2466/14.02.PR0.114k14w0

Spector, P. E. (1997). Job satisfaction: Application, assessment, causes, and consequences. Sage.

Suh, E. M., Diener, E. D., \& Updegraff, J. A. (2008). From culture to priming conditions: Self-construal influences on life satisfaction judgments. Journal of Cross-Cultural Psychology, 39(1), 3-15. https:/ / doi.org/10.1177/0022022107311769

Triandis, H. C. (1989). The self and social behavior in differing cultural contexts. Psychological Review, 96(3), 506-520. https:/ / doi.org/10.1037/0033-295X.96.3.506

Triandis, H. C. (2004). The many dimensions of culture. Academy of Management Perspectives, 18(1), 88-93. https://doi.org/10.5465/ame.2004.12689599

Uskul, A. K., Hynie, M., \& Lalonde, R. N. (2004). Interdependence as a mediator between culture and interpersonal closeness for Euro-Canadians and Turks. Journal of Cross-Cultural Psychology, 35(2), $174-191$. https://doi.org/10.1177/0022022103262243

Veldman, I., Admiraal, W., van Tartwijk, J., Mainhard, T., \& Wubbels, T. (2016). Veteran teachers' job satisfaction as a function of personal demands and resources in the relationships with their students. Teachers and Teaching, 22(8), 913-926. https:/ / doi.org/10.1080/13540602.2016.1200546

Vroom, V. H. (1982). Work and motivation (Rev. ed.). Krieger Publishing Company.

Warr, P. B. (2007). Work, happiness and unhappiness. Earlbaum.

Wei, X., Shen, P., Li, T., \& Liu, X. (2020). Self-construal mediates the impact of job burnout on life satisfaction and Chinese happiness. Current Psychology, 1-12. https:/ / doi.org/10.1007/s12144-020-00735-y

Weiss, D. J. , Dawis, R. V. , England, G. W. , \& Lofquist, L. H. (1967). Manual for the minnesota satisfaction questionnaire. University of Minnesota, Industrial Relation Center.

Yamaguchi, A., \& Kim, M. S. (2015). Effects of self-construal and its relationship with subjective well-being across cultures. Journal of Health Psychology, 20(1), 13-26. https:/ / doi.org/10.1177/1359105313496448

Yetim, N., \& Yetim, U. (2006). The cultural orientations of entrepreneurs and employees' job satisfaction: The Turkish small and medium sized enterprises (SMEs) case. Social Indicators Research, 77(2), $257-286$. https://doi.org/10.1007/s11205-005-4851-x 
Yu, X., Zhou, Z., Fan, G., Yu, Y., \& Peng, J. (2016). Collective and individual self-esteem mediate the effect of self-construals on subjective well-being of undergraduate students in China. Applied Research in Quality of Life, 11(1), 209-219. https:/ / doi.org/10.1007/s11482-014-9362-y

Zembylas, M., \& Papanastasiou, E. (2004). Job satisfaction among school teachers in Cyprus. Journal of Educational Administration, 42(3), 357-374. https:/ / doi.org/10.1108/09578230410534676 